\title{
Os exames nacionais e as Escolas: um ranking de interrogações*
}

B OM DIA A TODOS. GOSTARIA DE COMEÇAR por agradecer - não sei, a bem da verdade, se agradeça, se maldiga - o convite que o professor Paulo Ribeiro Claro me formulou para estar aqui. Acrescentaria que nada me qualifica de modo especial para me encontrar "deste lado" - eu, que sempre estive desse -, a não ser a vontade de um dos organizadores deste fórum em elevar a vox populi à prestigiada tribuna académica. Foi na sequência de uma conversa informal com o Professor Ribeiro Claro sobre a publicitação dos resultados dos exames nacionais do $12^{\circ}$ ano, cujo fragor foi audivel em planos diversos da Sociedade Portuguesa, que Ihe surgiu a ideia de procurar o testemunho de um professor de uma escola secundária - no caso em apreço, a Escola Secundária Mouzinho da Silveira (Portalegre). Mas esta, devido ao "pouco honroso" posicionamento nos diversos rankings mediaticamente construídos, estará longe de constituir um caso eventualmente susceptivel de emulação por outras organizações educativas - na retórica ministerial, não constituirá, em definitivo, um caso de "boas práticas". Foi, então, o convite justificado como uma tentativa para percepcionar o modo como aqueles resultados teriam sido apropriados pelos professores da minha escola, e em que medida condicionaram ou alteraram as respectivas práticas. Confesso que, a esta narrativa particularmente localizada, preferi devolver para a generalidade do campo educativo a discussão sobre os exames nacionais. Faço-o sob a forma de algumas interrogações que povoam o meu - e provavelmente o vosso - quotidiano profissional, cujas respostas apenas procurarei esboçar, enquadrar, e não formular em definitivo. Faço-o de um modo que não é neutro, assepticamente neutro, mas a partir de uma visão que assume a Escola Pública, e para todos os públicos (universal, portanto), como um modelo fecundo que, longe de esgotado, aguarda apenas adequada revitalização.

Uma primeira questão, que me parece óbvia, é para que servem os (estes) exames? Mais do que a certificação de saberes ou o estímulo da confiança que os actores sociais devem depositar nas organizações educativas, os exames nacionais cumprem a primordial missão de escalonar os alunos que a eles se sujeitam, o que se obtém pela (presumida) aferição dos conhecimentos detidos pelos alunos em áreas disciplinares específicas. Está, então, em causa a vertente instrutiva do processo educativo que tem lugar em contexto escolar, omitindo-se todas as outras que, na retórica normativa, se posicionam como nucleares.

Sendo verdade que a vocação instrutiva, que acompanha a Escola desde a sua fundação, é, ainda hoje, de enorme importância, as múltiplas aprendizagens que aos alunos são facultadas transcendem-na largamente. Mesmo o "simples acto de assimilar o que é transmitido" a que alguns gostariam, ainda hoje, de reduzir a missão da Escola - vem sendo (mais normativamente do que na prática, a bem da verdade) substituído pela aquisição, por parte dos alunos, de um conjunto de competências essenciais, relativamente à qual os conteúdos programáticos são essencialmente instrumentais. Uma das razões que vem contribuindo para que esta intenção, reiteradamente legislada, não seja apropriada pelos professores para definitivamente transformar a sua prática pedagógica é a existência, com a importância, que se Ihes reconhece, dos exames nacionais, destes exames nacionais. Essa ausência de transformação é visível não só no ensino secundário, mas também, por um efeito de contaminação ("licealização"), no ensino básico - basta verificar a não observância do disposto no Despacho Normativo 98A/92 (recentemente revogado), em que a principal modalidade de avaliação, a formativa, vem sendo sistematicamente preterida pela avaliação sumativa. Imagine-se que efeito teria a implementação da peregrina ideia de estender a avaliação sumativa externa aos anos terminais dos três ciclos do ensino básico, que, neste momento pré-eleitoral, é, por alguns, prometida!

Mas que fazer se os exames nacionais ora tão exaltados como instrumentos objectivos e fiáveis para medir o que é apreendido pelos alunos - efectivamente não avaliam a capacidade de um aluno se relacionar com os outros, de ser solidário, de cooperar, de ser autónomo, de ser honesto, de criticar, de ser civicamente responsável, tudo finalidades educativas plasmadas nos mais diversos documentos legais que regulam a vida das Escolas e dos seus alunos? Substituir duas horas de Educação Física por duas horas suplementares de 
Matemática ou Química, como a Fenprof sugere que algumas instituiçōes educativas particulares fazem no $12^{\circ}$. ano ("Jornal da Fenprof", $n^{\circ}$. 175, p. 20)? Atribuir uma hora suplementar às disciplinas de Matemática, Física e Química e aulas práticas de preparação para os exames nacionais desde Outubro, como faz o Externato Ribadouro, recordista de colocação de alunos no curso de Medicina ("Público", 20/10/2001)? Eliminar, como fez George W. Bush, do currículo americano a disciplina de "Educação Ambiental" por a considerar "apenas eficaz em propaganda ambientalista", reinvestindo o dinheiro nas áreas da Matemática e da Lingua Materna?

Parecendo-me, então, assente que os exames nacionais pouco ou nada medem do que de nuclear se passa, ou deveria passar de acordo com o imaginário normativo, nas organizações educativas, na medida em que reduzem a avaliação à classificação e seriação (de modo, aliás, algo arbitrário), surge como indispensável repensar a existência dos exames nacionais, pelos menos destes exames nacionais.

Uma segunda questão que me parece pertinente é a quem aproveitou a divulgação dos resultados dos exames nacionais do $12^{\circ}$ ano? No pretérito dia 27 de Agosto de 2001, o jornal "Público" apresentava, em tom eufórico ("salto civilizacional" nas palavras do seu director, "momento fundador" segundo António Barreto), os resultados generalizados dos exames nacionais do $12^{\circ}$ ano. Mas quem exigiu tal divulgação? Os principais intervenientes no processo educativo, como os professores, os alunos ou os pais (vide posiçẫo crítica da CONFAP, amplamente difundida)? Não! 0 que é verdadeiramente espantoso é que ela foi induzida por uma auto-reclamada elite, aconchegada às colunas dos principais periódicos do pais, onde mantêm, de há muito, avença certa, que produz, nas palavras de António Nóvoa, o "imaginário dominante", investida de um mandato social que ninguém lhe atribuiu! É curioso verificar que, recentemente e ao arrepio deste entusiasmo, o Pais de Gales e a Irlanda do Norte aban- donaram a divulgação de rankings, pois aquela não só não produziu as melhorias esperadas no sistema educativo (através da potencial emulação das escolas que apresentavam melhores resultados), como induziu naquele efeitos perversos, criando um pouco saudável clima de concorrência entre Escolas (“Jornal da Fenprof", n’. 175, p. 20).

Enquanto professor - e apesar da opinião que já expendi sobre os exames, não ignoro a sua existência - admito que será relevante reflectir com os restantes elementos da Comunidade, em sede, por exemplo, de Assembleia de Escola, sobre os resultados dos nossos alunos nas provas nacionais, eventualmente enquadrados por dados regionais ou nacionais. Mas a sua divulgação generalizada, descontextualizada, "liofilizada" (como Ihe chamou Joaquim Azevedo), a quem aproveitou?

Alguns dos que exigiram ou se congratularam com a publicitação dos resultados dos exames - como Pedro Arroja, João Carlos Espada ou Mário Pinto são, de há muito, arautos do fim do monopólio estatal da educação. Fazem-no não só em nome do "direito que assiste às familias de escolherem a melhor escola para os seus filhos", mas também em nome da "superior capacidade de gestẫo do sector privado" - nas palavras de Mário Pinto ("Público", 3/09/2001), "as escolas privadas comprovam a tese de que a iniciativa privada, ou social, ganha à iniciativa do Estado em excelência", ou, nas de Pedro Arroja (citando Milton Friedman, em Arroja, P. (1998). "Ensino Básico e Financiamento: a solução dos cupões de educação". In Colóquio/Educação e Sociedade, $n^{\circ}$. 4 da Nova Série, pp. 96-106), "aquilo que custa 3 no sector público custa 1 no sector privado"!

É, no entanto, necessário esclarecer que a promoção do mercado não impli$\mathrm{ca}$, necessariamente, a privatização do sistema (cf. Dale, R. (1994). "A promoção do mercado educacional e a polarização da educação". In Educação, Sociedade e Culturas, $n^{\circ}$. 2, pp. 109139; Whitty, G. (1996). “Autonomia da Escola e a escolha parental: direitos do consumidor versus direitos do cidadão na política educativa contemporânea". In Educação, Sociedade e Culturas, $n^{\circ}$. 6, pp. 115-139; Estêvăo, C. V. (1998). "Políticas de privatização e educação". In Educação, Sociedade e Culturas, $n^{\circ}$. 9, pp. 69-94). Tentando enquadrar esta posição internacionalmente (cf. Barroso, J. (1998). "Descentralização e autonomia: devolver o sentido cívico e comunitário à escola pública". In Colóquio/Educação e Sociedade, $n^{\circ} .4$ da Nova Série, pp. 32-58; Barroso, J. (1999). "Regulação e autonomia da escola pública: o papel do Estado, dos Professores e dos Pais". In Inovaçầo, $n^{\circ}$. 12, pp. 9-33), recorda-se que data dos finais dos anos oitenta, nomeadamente em paises anglo-saxónicos (Austrália, Nova Zelândia e Reino Unido), uma alteração qualitativamente importante do papel do Estado no sector da Educação, com a delegação de poderes da administração central nos niveis regional e local. O consequente aumento de autonomia das escolas foi acompanhado por novas práticas de gestão, consubstanciadas no modelo designado por "self/local management school". Formas mais radicais de gestão autónoma das escolas foram, no Reino Unido, as "grant-maintained schools" (escolas autónomas subvencionadas) que se caracterizavam por, após votação dos pais, haverem abandonado a dependência das autoridades locais, passando a ser financiadas e controladas por uma agência central. Dado que tais alterações se processaram em Escolas Públicas, é, para Roger Dale, cada vez mais inadequada a distinção público-privado, preferindo, a esta antinomia, a designação de "quase-mercado". Dois dos elementos estruturantes deste "quasemercado" são a livre matrícula, já citada, e o financiamento por aluno ("Quanto custa um aluno?, titulava João Carlos Espada um artigo no "Expresso", de 26/01/2002). A este é possível associar a proposta, ora muito actual, do "cheque-educaçāo" (ou "voucher", ou "cupão-educação"), que consiste numa verba que o Estado atribuiria à família do aluno para ser utilizada na escola pública ou privada da sua preferência. 0 risco de, por esta via, se estar a efectivamente a subsidiar a frequência das 
mais procuradas escolas privadas por parte dos filhos-família não é virtual. De acrescentar, ainda, que o estudo que Martin Carnoy (citado por António Nóvoa, em artigo do "Correio da Educação", de 19/11/2001) fez da realidade chilena, onde há mais de vinte anos há um plano nacional de "vouchers", não evidencia qualquer efeito positivo de tal politica no rendimento escolar dos alunos - é bom recordar que um dos argumentos frequentemente aduzidos por quem defende um mercado da educação é o pressuposto de que a concorrência entre escolas gera necessariamente melhoria na qualidade do ensino! Outra questão que também não pode ser escamoteada é a possibilidade que, num mercado aberto, (pelo menos) as escolas privadas teriam - se é que não têm já - de seleccionar os seus alunos com base em critérios de natureza social (não aceitação de alunos que potencialmente possam perturbar a ordem instituída) ou meritocráticos (instituição de provas de acesso, de modo a eliminar aqueles que fariam baixar os padrões médios de desempenho da Escola).

Creio, pois, que é perceptível que o ruído subsequente à publicação dos rankings das escolas gerou na sociedade portuguesa expectativas que tenderầo a estimular a liberalização do sector da educação; aliás, o discurso que é já audivel sobre a necessidade de restringir os gastos na área social, pela difícil condição das contas públicas, poderá legitimar tal decisão. Consequências diversas são possiveis: contratação de uma série de serviços ao sector privado ("outsourcing"); expansão dos contratos de associação com instituições educativas de direito privado - só na Região Centro, no ano de dois mil, tais contratos custaram ao erário público mais de treze milhões de contos ("Público", 10/10/2001); um novo modelo de gestão da Escola Pública ou, na sequência do processo de desacreditação que a Escola Pública vem sofrendo (e para o qual a publicitação dos rankings também contribuiu), modos mais radicais de organizar a escolarização como o "homeschooling" (que representa nos E.U.A. perto de um milhão de alunos) ou escolas confessionais que reclamam programas que respeitem integralmente as respectivas crenças religiosas (é conhecida a decisão de algumas escolas americanas, com estas caracteristicas ultra-conservadoras, de retirarem dos programas de Ciências a darwinista "teoria da evolução das espécies", por contrariar a letra bíblica, ou a recente proibição da leitura dos livros de Harry Potter que sessenta escolas australianas "Adventistas do $7^{\circ}$. Dia" fizeram aos seus alunos, por, supostamente, encorajarem as crianças a iniciar-se no mundo da magia negra!).

Para ilustrar as actuais tendências nos países anglo-saxónicos, três exemplos parecem-me, ainda, pertinentes. Em Inglaterra, o trabalhista Tony Blair, apostado em ver melhorado o desempenho de trinta escolas "más", convidou empresas privadas a "assessorarem" a sua gestão ("Público", 3/01/2002). Nos E.U.A., na sequência da aprovação da que é tida como a maior reforma educativa das últimas décadas, estabelecimentos de ensino que apresentem recorrentemente maus resultados correm o risco se sofrer fortes sanções, que podem incluir a substituição total do pessoal docente ("Público", 20/12/2001)! No Estado de Filadélfia (E.U.A.), o governador quer entregar a gestão de um elevado número de escolas problemáticas (envolvendo cerca de 210.000 alunos, maioritariamente pobres) à Edison Schools Inc., de modo a elevar a "performance" do Estado. Em causa poderá estar um contrato da ordem de 100 milhões de dólares ("Público", 30/12/2001), o que vem confirmar a tese de que o sector da Educação é um "mercado apetecivel"!

Uma última interrogação: como reagir a esta aragem liberalizadora?

No pressuposto, que é meu, de que o Ensino deve continuar essencialmente na esfera pública, assumindo os outros sub-sistemas um papel supletivo, parece-me essencial organizar um movimento de resistência. Neste, um papel insubstituível deverá caber aos professores que, numa postura de maior entrega profissional, de maior exigência para com a tutela e maior abertura à Comunidade, deverão contribuir para a

\section{demonstração de que a Escola Pública}

ainda é viável. Atrevo-me a deixar algumas sugestões para atingir tal desiderato:

- exigir à administração educativa que crie condiçōes para a existência de Escolas com maior autonomia (fazendo sair esta do normativo onde tem permanecido anestesiada), sem se demitir das obrigações que tem para com aquelas. Isto é, mantendo uma função reguladora do sistema educativo (fundamental para evitar/minimizar o surgimento de situações de desigualdade, potenciadas pela crescente intervenção do mercado neste sector) e não desinvestindo nele (situaçăo típica de sistemas mais "liberalizados"), deve acreditar que os professores, os alunos, os pais e outros elementos das Comunidades em que as Escolas se inscrevem são capazes de assegurar meIhor muitas das actuais atribuições da administração educativa;

- para tal, também é necessário que nas Escolas se criem condições para 0 aparecimento de verdadeiras comunidades educativas, de parcerias várias, de projectos de Escola construídos e depois apropriados pelos vários actores que nela evoluem, que não resultem prenhes de intenções e vazios de sentido;

- apostar numa formação de professores inicial e contínua substancialmente diversa da que existe, de modo que, a par da competência científica e pedagógica, se estimule o carácter cooperativo do trabalho docente e se sensibilize aqueles para as dimensões organizacionais da Escola;

- exigir aos professores dedicação profissional exclusiva à escola onde trabalham, acreditando e demonstrando que aquela constitui o espaço onde os problemas de aprendizagem dos alunos se podem, efectivamente, resolver - tal implica recusar e combater o recurso dos nossos alunos às iniquas explicações, que mais não são do que uma forma subtil de privatizar o ensino, até pelo descrédito 
em que mergulham a instituição escolar;

- reformular a carreira docente, em que o único critério para atingir 0 topo daquela não seja o de gozar de suficiente saúde. Esgotado o modelo generoso de que todos os professores são bons - ou, mais exactamente, que satisfazem -, urge a discussão sob o modo de encontrar uma avaliação do trabalho docente, que passe sobretudo pelo trabalho realizado na Escola, desejavelmente cooperativo, e não, como afirmava recentemente Miguel Santos Guerra, pela "dimensão da pasta de diplomas que o professor acumula".
É que uma Escola Pública melhor - e cuja imagem que projecta seja, necessariamente, melhor - necessita urgentemente de melhores e mais empenhados professores, de melhor e mais empenhado Estado, de melhor e mais empenhada Comunidade!...

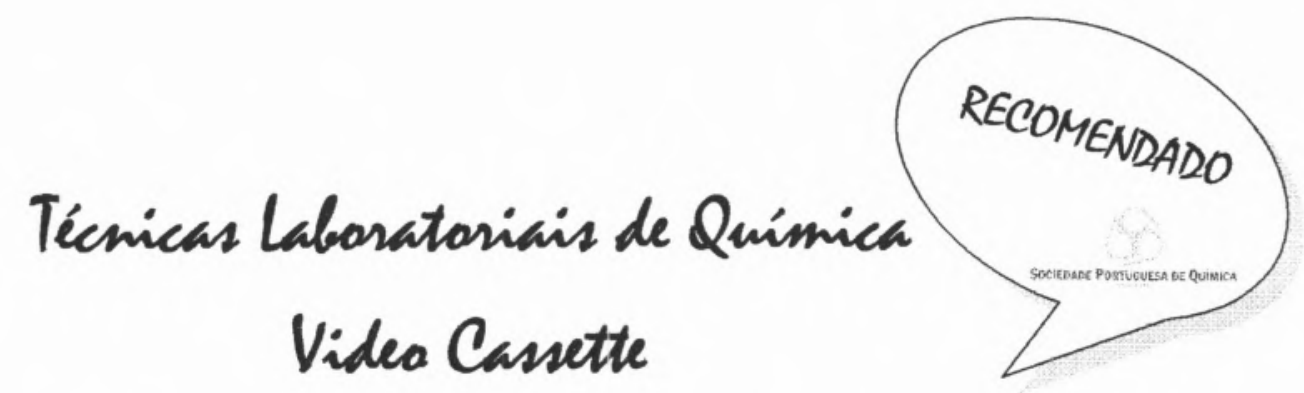

Com 7 blocos curtos e independentes, este trabalho foi concebido para apoiar as aulas de Técnicas Laboratoriais de Química destinadas a alunos do Ensino Secundário e das cadeiras introdutórias de Química do Ensino Superior. Os procedimentos apresentados são clássicos, simples e adequados para estes níveis de ensino, onde a transparência dos princípios químicos a ilustrar e a necessidade de adopção de boas práticas laboratoriais são da maior importância formativa.

\section{Índice}

Pesagem e Preparação de Soluções (11 minutos) Operação de balanças técnicas e de precisão Preparação de soluções rigorosas enão rigorosas

Análise Volumétrica Quantitativa (11 minutos)

Operação com pipetas e buretas

Titulações manuais

Recristalização e Fïtração (24 minutos)

Recristalização por dissolução e arrefecimento

Filtração em papel e à trompa

Filtração a quente

ExtracçãoLiquido -Liquido (7 minutos)

Operação com ampolas de decantação

Destilação (23 minutos)

Destilações simples, fraccionada,

a pressão reduzida e por arrastamento de vapor

TLC e Pontos de Fusão (9 minutos)

Cromatografia de Camada Fina

Enchimento de capilares para p.f.

Sopragem de Vidro (11 minutos)

Estirar tubos capilares

Cortar e dobrar tubos de vidro

Demonstração do fabrico e reparação de material de

vidro executada por sopradores de vidro profissionais do IST.

\author{
Ficha Técnica \\ Coordenação \\ Carlos Romão \\ Hermínio Diogo \\ Texto e Locução \\ Carlos Romão \\ Execução Laboratorial \\ Hermínio Diogo \\ João Paulo Telo \\ Conceição Mesquita \\ João Ferreira \\ Carlos Nuno \\ José Luis Rodrigues \\ Filmagem e Montagem Video \\ Luís Raposo \\ Anabela Martins \\ Hermínio Costa \\ Joaquim Pinto \\ Produção \\ Núcleo de Audio Visuais \\ do IST \\ Apresentação e Duração \\ Ih 36min; Cassette VHS \\ Distribuição Exclusiva \\ Sociedade Portuguesa de Química
}

Encomendas à SPQ, Av. da República 37, 4, 1050 Lisboa

Tel: 217934637 / Fax: 217952349

Preço: Instituições e não sócios $7500 \$ 00$ + IVA + portes

Sócios $6000 \$ 00+$ IVA + portes 